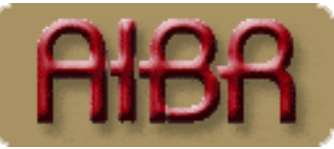

REVISTA DE ANTROPOLOGÍA IBEROAMERICANA

ESTIMADO LECTOR/A:

GRACIAS POR DESCARGAR ESTE ARTÍCULO. EL TEXTO QUE ESTÁ A PUNTO DE CONSULTAR ES DE ACCESO LIBRE Y GRATUITO GRACIAS AL TRABAJO Y LA COLABORACIÓN DESINTERESADA DE UN AMPLIO COLECTIVO DE PROFESIONALES.

USTED PUEDE AYUDARNOS A INCREMENTAR LA CALIDAD Y A MANTENER LA LIBRE DIFUSIÓN DE LOS CONTENIDOS DE ESTA REVISTA A TRAVÉS DE SU INSCRIPCIÓN A LA ASOCIACIÓN AIBR:

http://www.aibr.org/antropologia/aibr/socios.php

La asociación a AIBR tiene un coste mínimo al año, y le proporcionará las siguientes ventajas y privilegios:

1. Recibir en su domicilio la revista impresa, en Europa y América (tres números anuales), así como todas las novedades relativas al funcionamiento de la asociación.

2. Recibir en su domicilio, a precio especial o de forma gratuita, cuantas publicaciones adicionales edite la asociación.

3. Derecho a voto en las asambleas de socios, así como a presentarse como candidato a la elección de su Junta Directiva.

4. Recibir el boletín de socios (tres números anuales), así como la información económica relativa a cuentas anuales de la asociación.

5. Beneficiarse de las reducciones de precio en congresos, cursos, libros y todos aquellos convenios a los que a nivel corporativo AIBR llegue con otras entidades. En este momento, existen los siguientes acuerdos:

o Reducción de un $20 \%$ en el precio de todos los libros publicados por la editorial MELUSINA.

o Reducción de un $20 \%$ en el precio de todos los libros publicados por la editorial SEPHA.

o Reducción de un 30\% en el precio de todos los libros publicados por la editorial GRAN VÍA.

o Derecho a cuota reducida en los congresos trianuales de la FAAEE (España) y a los bianuales de la Sociedad Española de Antropología Aplicada.

o Derecho a cuota reducida en los congresos la IUAES.

6. Promoción gratuita, tanto a través de la revista electrónica como de la revista impresa, de aquellas publicaciones de las que sea autor y que estén registradas con ISBN. La difusión se realiza entre más de 5.000 antropólogos suscritos a la revista.

7. Cuenta de correo electrónico ilimitada de la forma socio@aibr.org, para consultar a través de webmail o cualquier programa externo.

8. Espacio para web personal de la forma http://www.aibr.org/(directorio)/(nombre) y cuenta propia de ftp.

9. Acceso con clave a todos los documentos de la Intranet de socios de AIBR, incluida la consulta a artículos en proceso de evaluación de la revista AIBR.

10. Promoción gratuita a través de la revista (banner rotativo y reseña) de aquellos eventos, congresos, conferencias o cursos en los que usted forme parte del comité organizador.

11. Opción a formar parte como evaluador de los artículos recibidos por la revista.

IMPORTE DE LA CUOTA ANUAL: Hasta diciembre de 2008, la cuota única anual es de 32 (euros). Su validez es de un año a partir del pago de la cuota. Por favor, revise la actualización de cuotas en nuestra web. 


\title{
AlB la caroca andaluza O EL INGENIO www.aibr.org HUMORÍSTICO ACOTADO POR EL DECORO. LECTURA ETNOHISTÓRICA
}

\section{José Antonio González Alcantud}

Universidad de Granada

\begin{abstract}
Resumen
Los pliegos de cordel y las carocas constituyeron una característica exposición de humor popular en la Andalucía del siglo XIX (España). Su eficacia simbólica se generalizó al convertirse en eco de noticias de sucesos contemporáneos, en las narraciones históricas o en mitografías religiosas. Este texto muestra una etnografía histórica de estos elementos como vehículo satírico del debate político, religioso y social, y revive la manera en que se utilizan actualmente. Desde su popularización hasta el momento actual, pasando por su prohibición en épocas de dictadura, se han convertido en un elemento que oscila entre el decoro y el humor negro andaluz, conocido popularmente con el nombre de "malafollá".
\end{abstract}

\section{Palabras clave}

Caroca, pliego de cordel, humor, decoro, malafollá

\begin{abstract}
The "Pliegos de cordel" and the "carocas" became a traditional exhibit of the popular humor in the XIX century, in the region of Andalucía (Spain). Their symbolic effectiveness had spread out as a reflection of current affairs, historical narrations and religious myths. This text is an ethno historical sample of these elements; as a satiric vehicle of political, religious and social debate, and also revives the way in which they are currently used. They were censured during the dictatorship periods and they become a feature of good taste but also of black humor in Andalucía, that is also known as "malafollá".
\end{abstract}

Key words

Caroca, pliego de cordel, humor, good taste, malafollá

Recibido: 15 de Octubre de 2007

Aceptado: 12 de Diciembre de 2007

os caminos de las representaciones gráficas en la plaza pública transcurrieron durante mucho tiempo por los pliegos de cordel. El dispositivo de los mismos se fue trasladando desde la teatralidad de la lectura salmodiada acompañada de un puntero en la plaza, antes de la generalización de la imprenta, hasta los pliegos impresos y vendidos en la misma plaza pública para consumo privado. Sucesos particulares acababan convertidos por esta vía en verdaderos lugares comunes del mito popular. Lo trágico y lo legendario en especial alcanzaban de lleno 
a estas formas de narración romanceada con apoyo gráfico. Escribió Caro Baroja (1969) con la vista puesta en los pliegos de cordel barrocos: "Si con frecuencia su continente es un tanto desastrado, su contenido ostenta indudables valores dramáticos, humanos en general. Refleja las inquietudes de una gran masa, del pueblo español meridional, o meridionalizado en una época oscura y decisiva en su devenir". Obritas escritas en papel barato, que debían reutilizar en muchas ocasiones las planchas de viejas ilustraciones, para ser producidas a bajo coste con el fin de llegar al gran público. De hecho, los préstamos de imágenes en los romances ayudaron en la repetición a reforzar su tradicionalidad (Alvar, 1989:82).

Empero, la razón fundamental de su éxito, y su consiguiente continuidad en el tiempo, procede de la eficacia simbólica de los contenidos. Esa eficacia funciona en el interior de una tríada temática. Generada tanto por las noticias de sucesos contemporáneos, como por las narraciones históricas y las mitografías religiosas. Los pliegos del primer tipo podían ser los más frescos, pues en ellos el ethos colectivo daba rienda suelta a sus pasiones y tortuosos manierismos; allí encontraban fondo y forma los absurdos de la vida diaria. Los acontecimientos históricos convertidos en narración mítica, donde se hacía indistinguible lo real de lo imaginado, contribuían a la cohesión ideológica de la nación emergente, tal que abstracción política. La religión, por su parte, estaba tentada a anclarse en lo pacato, aunque la lógica de la efectividad llevó a la explotación literaria de extrañezas y santos populares, tan populares como inverosímiles, en fuga hacia la heterodoxia. El pliego de cordel creaba y recreaba -dentro de una cierta estabilidad sólo modificada por novedades y sucesos- temas, tipos y secuencias narrativas gestados y / o aceptados por el ethos popular. Ahora bien, justo es reconocerlo, el pliego al estar mediado por la imprenta, regida por su connatural censura y autocensura, eliminaba las aristas de la moral popular, es decir la parte rabelesiana, impronunciable, grotesca, de la cultura. Los asuntos relacionados con el sexo o la política, por ejemplo, siendo los más proclives a la aprehensión rabelesiana, eran eludidos, por regla general. De hecho en el siglo XVII, se ha señalado, si bien el pueblo sentía con agudeza los trastornos políticos, manifestaba escasamente por vía satírica su oposición a los mismos, y solía acotar el humor en la vida cortesana de privados, ministros y validos (García de Enterría, 1973:308-ss). El umbral del humor grotesco no se traspasaba fácimente en este tiempo y medio, ya que en el comedimiento 
residía parte de la eficacia social del pliego. Comedimiento que, no obstante, no podía defraudar las expectativas truculentas, cursis o épicas... de un público endurecido por la vida diaria, y muy sensible, casi sensiblero, ante los avatares ajenos. Todo tan humano, tan popular, pero también tan comedido... El ingenio aquí ocupaba el papel estelar.

Otra prueba de ese tipo de literatura donde se mezclan viñetas y poemas breves la tenemos en las llamadas carocas $^{1}$ de la ciudad y entorno rural de Granada, en Andalucía. La temática de las carocas, a diferencia de los pliegos de cordel, es siempre humorística. Los orígenes de las carocas son oscuros, aunque cabe establecer algunas hipótesis sobre ellos. Por ejemplo, en el siglo XVII en el cortejo que anunciaba las fiestas del Corpus, presidido por una Tarasca, suerte de dragón originario del sur de Francia -de Tarascón, Arlés y Nimes, sobre todo- con una mujer a su lomo, venciéndolo- y con un acompañamiento de gigantes, danzantes y comediantes, iban carros que llevaban cartelones de tema pagano y humorístico. Así lo describe Miguel Garrido Atienza (1889), munícipe e historiador granadino de finales del siglo XIX:

"Caminaban á seguida à impulso de oculto mecanismo, ora graves; retozones á veces, bailadores otras, jinetes en ocasiones en tan bien imitados caballos, que no faltó "quien aun conociéndolos sin vida, la posesión de sus sillas deseara", bien sobre lujosos carros ó sobre andas, comúnmente siete gigantones, caprichosa o adecuadamente vestidos, y los cuales simbolizaban ó representaban ora las maldades que la visión apocalíptica recriminaba á las ciudades de Éfeso, Esmirna (....); ora gentílicas deidades, sacramentarios heresiarcas; bien los siete sabios de Grecia, ó los llamados vicios capitales, caballeros un año la soberbia sobre un pavo real, la avaricia en un buitre, la lujuria en un macho cabrío, la ira en un oso, la gula en un marrano, la envidia en un lebrel y la pereza sobre un borrico".

Seguía la comitiva con todo tipo de representaciones fantásticas, "y eran todos portadores de emblemas, símbolos, etc. Y daban a conocer su significado mediante las décimas, quintillas y cuartetos, que escritos en tarjetones cada uno en visible lugar llevaba". Siguiendo con la conexión probable con los pliegos de cordel,

\footnotetext{
${ }^{1}$ Joan Corominas consagra un largo artículo a la palabra caroca, a la que otorga un probable origen mozárabe, aunque sin aportar certezas, lo que explicaría su conservación en Andalucía. En cuanto a su significado sostiene que proviene de una composición dramática para solaz del vulgo, que posteriormente por contagio metonímico se aplicaba a los cuadros que acompañaban a los carros de comediantes que solían llegar con las fiestas del Corpus Christi (Corominas, Pascual, 1980).
} 
recordaremos que las quintillas de ciego habían sido una de la fórmulas poéticas preferidas de aquellos (García de Enterría, 1973:145). Mientras tanto, una de las plazas centrales de la ciudad, la de la Bibarrambla, se llenaba de altares efímeros, y de cuadros, a veces de pintores afamados, que ensalzaban la eucaristía y la religión católica. No obstante este esplendor barroco, asevera Garrido Atienza, que la monotonía y la falta de innovación se fueron imponiendo con el curso del tiempo. La transición hacia las carocas, por demás, estuvo favorecida por la abundancia en época moderna de jeroglíficos y alegorías, muchos de ellos profanos (Cuesta García de Leonardo, 1995). En el siglo XVIII esta monotonía de la temática católica, el uso de la emblemática citada, y sobre todo el espíritu de los tiempos, favorable a las ideas ilustradas, trajeron consigo el aumento de los temas profanos, que le disputaron el estrado a los religiosos:

\begin{abstract}
"Esos asuntos, motes y versos, no fueron siempre exclusivamente sagrados, pues más de una vez, formando extraño contraste, viéronse en esos decorados, alternando los santos del cielo católico con los dioses del Olimpo. La idea, el pensamiento exteriorizado en todo aquel conjunto de composiciones literarias y pictóricas, no fue tampoco todos los años un himno pura y directamente eucarístico: la preconización de marianas advocaciones, disquisiciones sobre el Apocalipsis ó enredados laberintos teológicos" (Cuesta García de Leonardo, 1995:63).
\end{abstract}

En línea similar solían aparecer igualmente, junto a los temas mitológicos y católicos, "pasajes de la historia (...) profana granadina". En definitiva, y ante el tedio de la repetición iba colándose el humor a través de la paganidad antigua y moderna.

Lo cierto es que fuese cual fuese su origen las carocas constituyeron un humor genuino de una plaza pública, la de Bibarrambla, que había conocido diferentes vicisitudes históricas, desde las justas nazaríes tardomedievales, que la hicieron célebre, incluso en el romancero, hasta las procesiones del Corpus Christi, con los exornos efímeros barrocos de los que hablamos. Su centralidad en la vida pública es obvia.

En torno a 1850, conforme el descreimiento avanzaba de manera ineluctable, fueron abandonadas definitivamente las temáticas religiosas que aún persistían en el XVIII siendo "sustituidos los lienzos de temas sagrados por cincuenta y seis paisajes que ocupaban la vuelta exterior" de la plaza (de Vicente, 1943). Un poeta local, José Salvador de Salvador, en 1850 justificaba de esta manera la sustitución de las carocas por cuadros históricos relacionados con la conquista de Granada: 
"Siempre hemos considerado muy mal efecto, impropios y algunas veces escandalosos los asuntos profanos que se han expuesto en los cuadros de la vuelta exterior ó frentes de la decoración de Bib-rambla, porque todo lo que es severo y solemne debe representarse del mismo modo; y así, por más que conociésemos las aficiones de algunos á las pinturas epigramáticas y picantes, como no escribíamos para ellos, sino para coadyuvar por nuestra parte á la celebración del aniversario de la Cena Santa... no tuvimos inconveniente en adoptar un asunto histórico gloria de nuestra nación, y muy especialmente de la ciudad que nos vio nacer..." (de Paula Valladar, 1886:74).

Siguiendo igualmente el ambiente de la época los lienzos representaron asuntos de la historia patriótica. "Innovación que -señala el periodista Luis de Vicente- no contó con muchos adeptos ya que, poco después, aparecen de una manera concreta las Ilamadas carocas". Continúa este autor dando cuenta del valor humorístico de las carocas en términos que vale la pena reproducir:

\begin{abstract}
"Composiciones pictóricas bufas, que satirizan los vicios de las gentes más conocidas. Desde entonces y a lo largo de muchos años, desfilaron por las carocas de Bib-Rambla, las escenas más grotescas y los hechos más salientes de la actualidad local. Se recogían en un sentido amplio y fino humorismo aquellos asuntos que más podían despertar el regocijo de los granadinos, que desfilaban íntegramente por la simpática plaza para gustar de espectáculo tan económico y al propio tiempo tan esperado. Aquellos tiempos de profundas luchas políticas ofrecían campo abandonado para ridiculizar actuaciones públicas de cualquier género y esto, plasmado en las carocas de Bib-Rambla, por las manos prestas de hábiles artistas, era siempre esperado como plato fuerte de nuestros famosos festejos".
\end{abstract}

El caso es que las carocas habían conocido un esplendor paralelo al de las fiestas del Corpus en los años ochenta del ochocientos. Los notables granadinos, como los de otras ciudades andaluzas, como Sevilla, habían calibrado la necesidad de promocionar las ferias ciudadanas, promoviendo desde diversas instancias, sobre todo desde la prensa, su recuperación (González Alcantud, 2004:107-119). En 1883 se lee en un diario local que "las fiestas del Corpus prometen estar este año brillantísimas, gracias a la iniciativa que la prensa de Granada ha tomado en bien de la industria, el comercio, las artes y la literatura" (Diario de Granada, 1883) . Incluso se fletarán trenes especiales para que vengan visitantes de las principales capitales andaluzas. Entre los atractivos del Corpus lógicamente estaban las carocas Los temas de las de ese año hacían mención a las elecciones, a las infidelidades matrimoniales, la embriaguez, el comercio, etc. Su aumento de valor social hace que sean incluidas en la programación oficial de las fiestas en términos como los que siguen: 


\begin{abstract}
"A las doce del mismo día el Excmo. Ayuntamiento, bajo mazas, precedido de pages, que llevarán el escudo de Granada, y acompañado de la guardia municipal, saldrá de las Casas Consistoriales, dirigiéndose á la plaza de Bibarrambla, donde ser hará entrega del decorado y adorno de la misma. Este adorno consistirá en una decoración al gusto árabe, con los cuadros profanos ó CAROCAS (en mayúscula en el original) y quintillas de costumbre, y en un altar central del mismo órden arquitectónico, en el que se colocarán las estatuas de los Reyes Católicos. En los ajimeces de las galerías se pondrán otras ocho estatuas de los personajes más célebres de la época de la conquista de Granada" (Programa de fiestas y Corpus Christi y feria de Granada, 1884).
\end{abstract}

Al año siguiente variará el decorado, que será "gótico", pero las carocas continuarán invariables (Programa de fiestas y Corpus Christi y feria de Granada, 1884). Sin embargo, cuando se produjo la coronación de Zorrilla como poeta nacional en la fiestas del Corpus de 1889, el decoro no debió hacer recomendable anunciar las carocas. Sólo puede leerse en el programa: "Desde las ocho á las doce de la noche, se verificará la poética y tradicional Velada de la Plaza de Bibarrambla, y al mismo tiempo la iluminación general por el vecindario, pudiendo visitarse los pintorescos y suntuosos altares que, según antigua costumbre, erigen los vecinos" (Programa de las Fiestas del Corpus, Coronación de Zorrilla y feria real de Granada, 1889) . Cierto que el propio Zorrilla había hecho observaciones irónicas sobre las fechas escogidas para coronarlo poeta nacional, tan cerca de la Tarasca y su cortejo circense, y sobre lo cerca que andaban lo sublime y lo grotesco en su coronación. Así que exigió no ser coronado físicamente con una corona de oro, como pretendían los organizadores, para no dar lugar a chanzas (González Alcantud, 2001:292-306). Al año siguiente, pasado este evento con repercusiones nacionales en que se movilizó toda la sociedad granadina, las carocas volverán a aparecer en el programa oficial de fiestas, y en la tradicional, plaza de Bibarrambla, en "una elegante galería con los cuadros burlescos o carocas, iluminada como toda la plaza, con una espléndida combinación de luces de gas" (Programa de las Fiestas del Corpus Christi y feria real de ganados en Granada, 1890).

El humor, en cualquier caso, se había convertido en la segunda mitad del ochocientos, en un vehículo privilegiado para el combate político, y así vemos que en esta época aparecen numerosas revistas, por regla general muy efímeras, de nombres tales como "Granada cómica", "Mefistófeles", "Granada alegre" o "Granada en cueros". Un humor, el de estas revistas "grotesco que llega a lo esperpéntico", que tiene por objeto privilegiado al campo de lo político, y que incluso contamina los ambientes "costumbristas" (Gamonal Torres, 1983:119). Aunque no se haya 
establecido una vinculación directa entre el mundo de las carocas y el de la prensa satírica de la segunda mitad del siglo XIX, con sus diatribas políticas, a todas luces este vínculo debió de existir. Al fin y al cabo, ambos se dirigían a la plaza pública, a la opinión pública. Por regla general, las carocas abordaban estereotipos sociales, procurando no aludir directamente a nadie en particular. Algún ejemplo entre otros. En la caroca número seis del año 1876 se representaban a algunas jóvenes elegantes que estaban arrodilladas delante de una bolsa llena de monedas, rezando la quintilla: "En la nueva religión/ Que el positivismo adora, / El jefe San Talegón,/ Santo de devoción/ de las jóvenes de ahora" (Diario de Granada, 1883). En las de 1884 un cuadro representaba "una anciana sentada en un sillón, á la que se acerca un hombre arrojando dos caños de lágrimas por los ojos", y en la quintilla se dice: "Si alguno se desconsuela / y se da por aludido, / puede tragarse la muela, / ó bien tomar el partido / de contárselo á su abuela". En otra, que presentaba a "un grupo de personas de ambos sexos, muy delgadas y en ademán triste", se lee el siguiente texto: "Los pasivos de Granada / que en el cuadro se han pintado / están con hambre atrasada, / y se convierten en nada/ a fuerza de hilar delgado". La que le sigue, de tono diferente, dibuja a "dos elegantes con sombrero en mano, peinados a raya y tufos y vestidos con levitón", que son descritos así: "Ya toman los elegantes / á la mujer por modelo, / y usan pulseras brillantes, / y cupidos en el pelo / y levita con volantes" (Carocas de los adornos de la Plaza de Bib-Rambla, 1876). Las posibilidades de identificación, no obstante, existían en la medida en que las conductas sociales en la época estaban muy estereotipadas a través de la vestimenta y otras fijaciones sociales. Pero difícilmente podían darse por aludidos quienes leían quintillas como estas.

Durante las dictaduras, tanto de Primo de Rivera como de Franco, las carocas fueron prohibidas por su marcada deriva política previa, orientada por las tensiones de aquel tiempo. El aumento de la confrontación política marcaba el deterioro del decorum. En 1929, terminada la dictadura de Miguel Primo, las carocas fueron recuperadas, gracias al Centro Artístico, que constituía el epicentro de la vida cultural de ciudad, al agrupar a intelectuales y elites, y que se había destacado socialmente como sociedad promotora de veladas, cabalgatas de Reyes Magos, recuperación de las fiestas del Corpus, de Carnaval, organización del festival de cante flamenco de 1922, etc. Pero esta recuperación, nos informa Luis de Vicente, lo 
fue "dentro de un tono mesurado y correcto, aunque siempre con marcada intención política", puesto que "las gestiones de los ayuntamientos, fueron desde luego el caballo de batalla". En 1950, pasado el primer embate de la dictadura franquista, tan enemiga, como todos regímenes autoritarios, del humor, especialmente del carnavalesco, volvieron las carocas a las fiestas granadinas, aunque hasta dos años después, en 1952, no volverán a ser colocadas en la plaza de Bibarrambla (de Vicente, 1952). La simplicidad de las carocas en el franquismo les había hecho perder fuerza irónica, y si se conservaban era por la fuerza del costumbrismo ideológico del régimen, que promocionaba ciertos rituales "típicos", y las carocas podían acogerse a esa categoría.

Con la restauración democrática las carocas regeneraron su lenguaje plástico y literario, sacándolas del sopor a que el franquismo las había cometido. Recordaremos aquí, por si sirviese para explicar los caminos propios del humor local, que aún hoy día en Granada se cultiva un tipo de humor social caracterizado como "negro" que responde a patrones sobre todo sarcásticos, y que se distingue de la "gracia" del humor sevillano. Suele ser incluso un lugar común para visitantes y propios comparar, marcando las distancias, en lo tocante a humor entre Sevilla y Granada (González Alcantud, 2003:14-34). A veces, ese humor, llamado popularmente "malafollá", se ve aparecer en las más logradas carocas, y el público autóctono sabe apreciarlo.

Pero lo cierto es que en todo régimen y situación las carocas son controladas por el Ayuntamiento. De esta forma no pierden el decorum. La prensa, en una tradición que arranca de tiempos recientes reproduce las carocas para publicitarlas. En los últimos años incluso algunos periódicos han promovido sus propias carocas, que no son expuestas en Bibarrambla, realizando concursos entre sus lectores. Es una risa tibia, que no obstante, sobre todo en los años de la democracia, se ha convertido en un ejercicio de ingenio, capaz de suscitar el humor, sin entrar en ataques políticos directos ni herir susceptibilidades particulares ni personales. De hecho, no existe ninguna protesta en los últimos años, realizadas por personas o colectivos ofendidos. En una sociedad que se ha habituado a denunciar todo aquello que considera que extralimita los derechos individuales o colectivos este es un logro del ingenio. Que recurre, justo es decirlo, al humor negro de la "malafollá". Ahí es donde está la chispa de esta formulación humorística. 
No obstante, nada está libre de las ridiculizaciones, algunas semi conscientes, que se le puedan escapar al humorista. Hace poco ocasión estando observando las carocas granadinas de la plaza de Bibarrambla, justo mientras las iban colocando la noche anterior a su inauguración unos operarios municipales, deparé en una que hacía alusión a un caso muy comentado en España: la quiebra de una sociedad de inversión filatélica, la cual había dejado en la ruina a mucho miles de personas, que habían perdido sus ahorros depositados en ella. Me reía de buena gana con la caroca, ya que la quiebra se parecía a un auténtico "toco mocho", un engaño pueblerino. En definitiva veía en este caso la persistencia de la España rural, con sus engaños y quimeras clásicos. Y sus aprovechados en pequeña escala finalmente corneados. Fuera modernidad, pues, y mucha España negra, era lo que yo veía. Cuando estaba riendo, digo, una pareja de avanzada edad, que estaba a mi lado absorta en la caroca que retrataba el fraude, me comentaron que ellos habían sido engañados por la citada empresa filatélica, y que habían perdido sus ahorros. Entonces enmudecí: habíamos pasado de la risa provocada por el ridículo colectivo expuesto en la plaza pública a la cruel realidad, con sus tragedias domésticas. Lógicamente los acompañé en sus sentimientos, y dejé de mirar aquella caroca con la misma guasa. Me sentí cohibido por la potencia mortífera del humor. En principio se trata de un humor controlado, cuya eficacia consiste en hacer arrancar sonrisas, no más, en el tratamiento decoroso de temas locales, o globales pero en su vertiente local. Su punto culminante sería la "malafollá", un juego irónico que nos satiriza con eficacia pero que no nos hiere. El juego humorístico concierne sobre todo al ingenio para sortear el decoro, la censura y el dolor/dolo ajeno. Se trata, pues, de un ejercicio de inteligencia humorístico que debe excluir la agresión.

La lucha contra las carocas, al margen de las dictaduras que las prohibieron o edulcoraron, no obstante ha existido en los ambientes pequeño burgueses más inclinados al decoro. Verbigracia, en una larga serie de artículos publicados por Elías Pelayo, otro notable local, en la revista La Alhambra en 1884 este eludía estudiar las carocas como parte de la regeneración del Corpus que entonces el mismo pregonaba (Pelayo, 1884). También Francisco de Paula Valladar, director de esa revista, intelectual relevante en la vida granadina, igualmente comprometido en la promoción de las fiestas del Corpus, era partidario de limitar o sustituir las carocas, a pesar de que él mismo contradiciéndose en su libro de 1886 sobre las fiestas 
centrales granadinas, reproduce las letras de algunas de ellas. De su propia cosecha reflexiona de Paula Valladar (1886:74):

\begin{abstract}
"El pensamiento de las poesías y pinturas burlescas ha sido casi siempre hacer ridícula crítica de costumbres, modas, etc., De exageración en exageración, se ha llegado algún año a ridiculizar á desgraciados idiotas ó poco favorecidos de la fortuna. En las carocas han aparecido para excitar la hilaridad del público, muchos de los desdichados que por su imbecilidad, su locura ó su decidida afición á las bebidas, se hicieron tristemente famosos. Una de las carocas de 1857, decía así: Por última vez Ropones/ cumple con la obligación,/ y aprovecha la ocasión/ de hacer, con sus libaciones/ menos viva la impresión" .
\end{abstract}

Este "mal gusto", hacedor de alusiones a los defectos físicos o morales de sujetos concretos, se manifestó hace pocos años, cuando los "cabezudos" de la "Pública", el cortejo procesional antes mencionado que anuncia las fiestas del Corpus, presidido por la Tarasca, reprodujo a Paniolla, un pobre hombre sin juicio que fue motivo de burlas de la chiquillería en el pasado, y que para asombro de muchos seguía viviendo, cuando se le daba por muerto, en un asilo de Granada. Paniolla había quedado ciego hacía muchos años por una broma que le habían gastado abusando de su estulticia. La máscara fue retirada, no así la del cabezón de Gabia, un hombre monstruoso fallecido mucho tiempo atrás, y del que no quedaba memoria viva. Las limitaciones morales del humor, de las que hablaba Charles Baudelaire, se miden con los vivos. La muerte toma su polisemia simbólica es el límite y censura del humor.

Finalmente, expondremos un caso etnográfico para ilustrar el uso humorístico, al par que político, realizado con las carocas en un pequeño pueblo del entorno de la ciudad de Granada, este último año de dos mil siete. El pueblecito que posee setecientos habitantes censados se halla a quince kilómetros de la capital, a la entrada de un extenso parque natural. Son varios los pueblos que bordean las montañas que componen este parque, y que tienen asiento histórico en el piedemonte de las mismas. Son pueblos pequeños, que sorprenden al visitante por su marcada ruralidad, a pesar de hallarse muy cercanos a la capital provincial. En la terminología usual, la gente de la ciudad suele considerar a sus habitantes muy "catetos", mientras los extranjeros tienen la sensación de encontrarse en lugares mucho más remotos como las agrestes Alpujarras. Pues bien, este pueblecillo llamado Nívar, se ha visto sometido a una fuerte tensión vecinal en medio de las últimas elecciones municipales habidas en España. Se descubrió que el lugar del 
pueblo más singular, el que le imprime su forma paisajística, llamado popularmente "cerro de Bartolo" o "del Castillo" 2 , coronado por unos restos de tumbas visigodas, había comenzado a ser urbanizado con el fin de instalar en él varias decenas de viviendas. El asunto fue a más ya que, y dada la naturaleza arqueológica del lugar, aparecieron restos humanos y de cerámica, que fueron llevados por los vecinos a la delegación de cultura del gobierno regional, competente en esta materia. Entonces el asunto saltó a la prensa local, que indagó en quiénes eran los propietarios y promotores de la urbanización de marras, y ante el asombro de la opinión pública se descubrió que uno de los propietarios era un veterano vecino del lugar, dirigente provincial de un partido de izquierda, con responsabilidades políticas en el parlamento nacional. La tensión subió en el pueblo dada la cercanía de las elecciones municipales, que lógicamente giraron de casa en casa y de familia en familia en torno a este affaire. El paso del tiempo demostró que había una gran complicidad de la mayor parte del pueblo con los promotores, dados los intereses crematísticos puestos en juego. Las tradicionales fiestas patronales dedicadas al Cristo de la Salud de mucho predicamento no sólo en el pueblo sino en la comarca se dice que en el pasado libró de una epidemia a un pueblo cercano- tuvieron por esta razón una dimensión conflictiva en este último verano de dos mil siete. Celebradas a muy pocos meses de haberse realizado las elecciones municipales y del escándalo urbanístico relatado, las carocas reflejaban en su mayor parte la frustración por no poder hacer la urbanización, recalificación de suelos en las que estaban puestas muchas expectativas de ganancia, así como los ataques, muy violentos a la "gente guapa" y al "concejal ese y su gayomba" a los que se hacían responsables del fracaso. Esta última era una alusión directa al concejal electo de un grupo de izquierda que se había distinguido en la defensa de la función cultural y patrimonial del cerro en litigio. Aquí podemos observar que cuando la plaza pública se arma de razones políticas el humor pierde su función liberadora y se convierte en un arma cargada de amargo sentido político que poco o nada puede hacer sonreír a quienes lo contemplan. Es claro que la vida local de las pequeñas localidades suele estar tanto o más tensionada que la vida de las más grandes. Se viven los

\footnotetext{
${ }^{2}$ Escribe una historiadora sobre el particular: "Actualmente existe un cerro denominado Castillo de Nívar o Castillejo donde debió existir la fortaleza árabe antes citada, de la cual no queda ni ruinas, a causa de un terremoto que experimentó esta zona en el año 1755". (Guerrero Lafuente, 1986:11). Popularmente siempre se supo que en este cerro aparecían "cosas de moros".
} 
problemas, no tanto imaginariamente, como en la lucha por los recursos con un grandes pasiones. Los numerosos pueblos de la provincia granadina siguen viviendo la política local con más tensión que la capital, y han dado lugar frecuentemente en la época democrática a enfrentamientos radicalizados en extremo. No puede extrañar oír en cualquier bar o peluquería maldiciones y agresiones verbales contra los contrarios que minan la vida familiar y social. Son muchos los ejemplos extraídos de la etnografía política granadina de las últimas décadas. Incluso se hizo célebre un pueblo alpujarreño donde padre e hija militaban en partidos diferentes, trasladando hasta lo ridículo sus tensiones personales a la vida pública. Sin embargo, en la capital los cambios de color político y de personas se han vivido con más relatividad, y no cabe reseñar casos como los de la provincia profunda.

Volvamos al humor y la muerte. Estos están mucho más cerca de lo que inicialmente pudiera pensarse (González Alcantud, 2006 y 1993:71-100). A Octavio Paz le intrigaban unas figurillas encontradas en una excavación mexicana, que parecían reírse a carcajadas hasta troncharse. Su verismo es vital. Señala Paz: "La relación entre la risa y el sacrificio es tan antigua como el rito mismo. La violencia sangrante de bacanales y saturnales se acompañaba casi siempre de gritos y grandes risotadas. La risa sacude al universo, lo que pone fuera de sí, revela sus entrañas. La risa terrible es manifestación divina. Como el sacrificio, la risa niega el trabajo" (Paz, 2004:16). Lo terrible de la risa reflejada en esas caras de terracota aparecidas en México en 1952, es su vivacidad. Según Octavio Paz, seguramente estaban asociadas a sacrificios humanos, en particular a los del juego de pelota, en los que quien perdía pagaba con su vida la pérdida. Humor cruel que encantaba a André Breton y a los surrealistas. Por demás, también el humor ha servido para ahuyentar el miedo al terror político. Recordaba el diputado y periodista Camille Desmoulins en pleno Terror revolucionario francés, que entre los antiguos atenienses además de existir como valores "el gusto a la libertad, la tolerancia o el espíritu democrático", tenían como valor propio "el saber reír" (Mossé, 2000:554). Desde el periódico Vieux Cordelier Desmoulins luchó por ese ideal democrático e irónico hasta que la guillotina segó su vida. Todo esto me hace recordar la risa final del protagonista de "El proceso" de Kafka en la versión cinematográfica de Orson Welles: mientras está 
en un hoyo el "procesado", esperando que los sicarios le lancen una bomba que acabe con su absurda vida, ríe y ríe hasta la hilaridad.

La risa, cercada por el terror, es nerviosa y mucho más estridente que la que pueden provocar las caricaturas romanas en terracota conservadas en el museo Vaticano o incluso que las caricaturas realizadas por el gran maestro Daumier sobre personajes públicos de su época. El humor nos sitúa ante el discurso último de la cultura humana, la política, y esta ante la muerte con su larga retahíla de sacrificios. Y el humor siempre está presto a sacrificar a alguien, de ahí la vigilancia y sagacidad que establecemos sobre él. Para evitar que salga desbocado por las plazas públicas, haciéndonos reír y reír sin parar mientras la parca siega nuestras vidas.

\section{Bibliografía}

Alvar, M.(1989). Estudios de literatura popular malagueña. Málaga. Diputación.

Caro Baroja, J. (1969). Ensayo sobre la literatura de cordel. Madrid.

Carocas de los adornos de la plaza de Bib-rambla (1876). Folleto.

Corominas, J. y Pascual, J.A. (1980). Diccionario crítico etimológico e hispánico. Vol I. Gredos. Madrid.

Cuesta García de Leonardo, M.J. (1995). Fiesta y arquitectura efímera en la Granada del siglo XVIII. Universidad de Granada.

de Paula Valladar, F. (1886). Estudio histórico-crítico de las fiestas del corpus de Granada. Imprenta la Lealtad. Granada

de Vicente, L. (1943). Tipismo y popularidad de las carocas de Bibarrambla. Granada en Corpus.

de Vicente, L.(1952) Vuelven las carocas. Granada en Corpus.

Diario de Granada (1833). 18 de mayo.

Diario de Granada (1883). 19 de mayo.

Gamonal Torres, M. A.(1983). La ilustración gráfica y la caricatura en la prensa granadina del siglo XIX. Diputación de Granada.

García de Enterría, M.C.(1973). Sociedad y pliegos de cordel en el barroco. Taurus. Madrid.

Garrido Atienza, M.(1990). Antiguallas granadinas. Las fiestas del corpus. Estudio preliminar de González Alcantud. Universidad de Granada.

González Alcantud, J.A. (1993). Humor y rito en andalucía. En González Alcantud. Agresión y rito y otros ensayos de antropología andaluza. Diputación de Granada. 
González Alcantud, J.A.(2001). La coronación de Zorrilla en la Alhambra como hipérbole social del héroe tardorromántico. En González Alcantud y Malpica Cuello (eds.) Pensar la Alhambra. Barcelona, Anthropos.

González Alcantud, J.A.(2003). Los andaluces y el humor. En: Rodríguez Becerra, Antropología de Andalucía. Sevilla. Publicaciones comunitarias Vol IX.

González Alcantud, J.A.(2004). Valladar o los adarves del non nato movimiento folclorista granadino. En: Viñes Millet, C. (ed.) Los sueños de un romántico. Francisco de Paula Valladar, 1852-1924. Granada. Casa de los Tiros, Caja General de Ahorros.

González Alcantud, J.A. (2006). Los combates de la ironía. Risas premodernas frente a excesos modernos. Barcelona, Anthropos.

Guerrero Lafuente, M.D.(1986). Nívar, noticias y documentos para su historia. Ayuntamiento de Nívar.

Mossé, C.(2000). Le rire contre la terreur. En Desclos (dir.) Le rire des grecs. Anthropologie du rire en grèce ancienne. Grenoble, Williom.

Paz, O.(2004). Risa y penitencia. En Paz, Medellín y Beverido. Magia de la risa. Universidad Veracruzana.

Pelayo, E.(1884). Las fiestas del Corpus. La Alhambra. Serie de veinte artículos.

Programa de las fiestas del Corpus Christi y feria de Granada (1884).

Programa de las fiestas del Corpus Christi y feria de Granada (1885).

Programa de las fiestas del Corpus, coronación de Zorrilla y feria real de Granada, (1889).

Programa de las fiestas del Corpus Christi y feria real de ganados en Granada, (1890). 